\title{
Tobacco Advertising, Promotion and Sponsorship in India and Indonesia: Present Regime and the Way Forward
}

\author{
Suchiti Chandra ${ }^{1}$, Arvind Vashishta Rinkoo ${ }^{2 *}$, Jagdish Kaur ${ }^{3}$, Vinayak Prasad ${ }^{4}$
}

\begin{abstract}
One of the important factors contributing to tobacco epidemic is tobacco advertising, promotion, and sponsorship (TAPS). TAPS is employed by tobacco industry to increase demand for its products, often through targeting specific groups or market segments. The World Health Organization Framework Convention on Tobacco Control (WHO FCTC) recommends implementation of comprehensive bans on TAPS as part of an effective set of tobacco control policies. Article 13 of the WHO FCTC and its guidelines mandate a comprehensive ban on all TAPS. Besides, TAPS ban is one of the MPOWER strategy and is included in the 'Best Buys' for effective tobacco control. However, many countries, especially low-income and middle-income countries, primarily implement only partial TAPS bans, allowing the tobacco industry to directly or indirectly advertise and promote its products via multiple media. This review article analyzes the current state of affairs in respect of TAPS in India and Indonesia, the two of the largest countries in the WHO South-East Asia Region of the world, and discusses the way forward to address the identified gaps in TAPS ban policy formulation and implementation focusing on strengthening its compliance and enforcement at the country level.
\end{abstract}

Keywords: Tobacco control- TAPS ban- South-East Asia Region- MPOWER- Best buys

Asian Pac J Cancer Prev, 22, Progress of Tobacco Control in the South-East Asia Region Suppl, 89-96

Setting the context

The global action plan for the prevention and control of noncommunicable diseases (NCDs) 2013-2020 calls for a $30 \%$ reduction by 2025 in the prevalence of tobacco use among people aged $\geq 15$ years (WHO, 2013b). However, current projections suggest that the Southeast Asia (SEA) Region is likely to fall short of this target (WHO, 2019). Home to about one-fourth of the world's population, the Region has more than 230 million adult smokers and 248 million adult smokeless tobacco users (WHO, 2019). To give a perspective, this comes to more than $20 \%$ of all adult tobacco smokers and more than $80 \%$ of all adult smokeless tobacco users globally. Diverse population groups across many SEA countries have high sociocultural acceptance of smokeless tobacco products (Kaur, Thamarangsi and Rinkoo, 2017). Moreover, only Thailand and Maldives are "upper middle income" countries; rest all the countries in the Region are "low- and middle-income countries" or "low-income countries", thus further contributing to huge economic burden of tobacco in the Region. In fact, the range of tobacco-attributable NCDs and economic costs thereof are a major burden to developing countries throughout this Region (WHO, 2020).

Commercial determinants of health are defined as 'strategies and approaches' used by the private sector to promote products and choices that are detrimental to health (Kickbusch et al., 2016). One of the important factors contributing to tobacco epidemic is tobacco advertising, promotion, and sponsorship (TAPS). TAPS is employed by the tobacco industry to increase demand for its products, often through targeting specific groups or market segments (WHO, 2013a). Youth are a crucial market for tobacco companies and are especially targeted through customized TAPS campaigns. Tailor-made campaigns are used to create brand associations that appeal to target audience and help in establishing brand loyalty among current tobacco users. Evidence suggests that exposure to TAPS contributes to increased tobacco consumption - this is true for smoking and smokeless tobacco products alike (WHO, 2018; WHO 2020). In fact, TAPS target the psychological and social desires of different population segments, such as peer approval, fashion, maturity, femininity, and masculinity, as applicable (WHO, 2013c). Over the years, big tobacco has successfully launched a range of marketing strategies to effectively communicate brand associations to the target segments, including campaigns on conventional media such as billboards, television, and radio, as well as on emerging platforms such as websites and social media (Stubbs, 2021).

Evidence suggests that different TAPS approaches

${ }^{1}$ Advocate and tobacco control legal expert, India. ${ }^{2}$ Regional Data Coordinator, TFI, WHO SEARO, India. ${ }^{3}$ Regional Advisor, Tobacco-Free Initiative, Regional Office for the South-East Asia, World Health Organization, India. ${ }^{4}$ Unit Head, No Tobacco, WHO HQ, Switzerland.*For Correspondence: docavr@gmail.com 
influence tobacco consumption related attitudes and behaviors of targeted population segments. These approaches include point-of-sale ( $\mathrm{PoS}$ ) advertising and promotion, sampling and value incentives, brand extension and brand sharing, packaging and product design features, product placement, sponsorship of sporting, cultural or even educational events and/or activities for individuals or groups (athletes or their teams/clubs, artists or their organizations, etc.) in exchange for publicity, and corporate social responsibility, to name a few. TAPS attempt to normalize tobacco use by depicting tobacco products as being no different from any of the other consumer products. This enhances social acceptability of tobacco use and makes it difficult to educate people about the many harms of tobacco consumption (WHO, 2013a). Packaging of tobacco products, including depiction of brand names, logos, colors, slogans, descriptions, and images, is especially crucial to the tobacco industry's marketing strategy. Evidence corroborates that these characteristics of packaging of tobacco products negatively influence users' beliefs and perceptions about the harms of these products. Studies suggest that packaging characteristics influence users' attitudes and beliefs towards different tobacco brands and contribute to brand loyalty. Notably, among the various types of organic growth strategies, a brand extension strategy usually leverages the parent brand to enter a new product category. However, the tobacco industry is using the strategy in its reverse format i.e. a new product is created to hamper and circumvent the existing TAPS ban (Stubbs, 2021).

The World Health Organization Framework Convention on Tobacco Control (WHO FCTC) recommends implementation of comprehensive bans on TAPS as part of an effective set of tobacco control policies. Article 13 of the WHO FCTC and its guidelines mandate a comprehensive ban on all TAPS (WHO 2013b). TAPS ban is one of the MPOWER strategy and is included in the 'Best Buys' for effective tobacco control (WHO, 2020). However, many countries, especially low-income and middle-income countries, primarily implement only partial TAPS bans, allowing the tobacco industry to directly or indirectly advertise and promote its products via multiple media (Septiono et al., 2021). Moreover, increasingly, a large proportion of tobacco advertising and promotion is being accomplished through emerging media such as websites and social media or at music and sports events which are increasingly becoming popular (Astuti and Freeman, 2018). Retail tobacco products advertising is another stumbling block in effective implementation of TAPS ban (Polanska and Kalet, 2021). Also, online and social media are borderless and can reach out to populations well beyond a country's administrative and regulatory borders. Thus, populations worldwide, including adolescents and children, are vulnerable to exposure to TAPS from countries with insufficient and weak legislation (Septiono et al, 2021). This has further aggravated in light of emerging and new tobacco products such as electronic nicotine delivery systems (ENDS), heated tobacco products (HTPs) and nicotine patches, and their easy availability and aggressive marketing online (Kaur and Rinkoo, 2017; Polanska and Kalet, 2021).
Moreover, even in countries with strong legislation on TAPS, effective implementation continues to be a major challenge.

This review article analyzes the current state of affairs in respect of TAPS in India and Indonesia, the two of the largest countries in the SEA Region, and discusses the way forward to address the identified gaps in TAPS ban policy formulation and implementation focusing on strengthening its compliance and enforcement at the country level.

\section{Where we stand} India

India is the second largest consumer of tobacco in the world with a myriad of tobacco products, both smoking and smokeless available in the market. Many popular betel-nut products are also consumed with tobacco. Section 5 of COTPA (Cigarettes and Other Tobacco Products Act 2003) is consistent with Article 13 of the WHO FCTC and bans all forms of direct and indirect tobacco advertisements. India ratified the WHO FCTC in 2004. National Tobacco Control Programme (NTCP) is being implemented since 2007-08. The enforcement of COTPA provisions and WHO FCTC implementation is undertaken through an established mechanism at national and sub national level through NTCP.

Although COPTA prohibits most forms of tobacco advertising, including that appearing on television, radio, print media, and billboards, it does allow "on-pack advertising" and "PoS advertising" of tobacco products. With regard to PoS advertising, the law dictates the inclusion of a prominent health warning and that the display shall "only list the type of tobacco products available and no brand pack shot, brand name of the tobacco product or other promotional message and picture shall be displayed on the board. The display board shall not be backlit or illuminated in any manner." Despite this prohibition, full compliance with PoS-related rules is rare in India (Khariwala et al., 2016).

Further to COTPA, India has Cable Television Network Rules (CTVN), 1994, enforced by the Ministry of Information and Broadcasting (MoIB) which restrict the advertisement of "cigarettes, tobacco products, wine, alcohol, liquor, or other intoxicants." These rules were amended in 1995 to include "a product that uses a brand name or logo, which is also used for cigarettes, tobacco products, wine, alcohol, liquor or other intoxicants, may be advertised on cable service subject to limited conditions." These rules were further amended in 2009 to permit the product advertisements found to be "genuine brand extensions" of a tobacco product, subject to preview and certification by the Central Board of Film Certification (CBFC) as suitable for unrestricted public exhibition. On June 17, 2010, another directive was issued by MoIB clearly directing all television channels to stop carrying any advertisement whatsoever of a product that uses a brand name or logo used for tobacco products. On September 15, 2020, MoIB again reverted its stand and issued an advisory that such advertisements would be previewed and certified by the CBFC to ascertain whether they are suitable for unrestricted public exhibition and 
are in accordance with stipulated conditions (Ministry of Information and Broadcasting, 2020). This contradiction between provisions under COTPA and the CTVN Rules led to the formation of Committee of Secretaries $(\mathrm{CoS})$ by the Government of India in 2012 to examine the issue of television advertisements on genuine brand extensions (brands sharing names with tobacco and alcohol products) as distinct from surrogate advertisement (indirect advertisement of tobacco and alcohol products) (Ministry of Information and Broadcasting, 2014). In view of the decisions of the CoS not publicly available, the prevailing ambiguity is of definite advantage to the tobacco industry which is unabatedly employing surrogate advertisements to promote its products.

The tobacco industry has strategically employed brand extension and brand sharing (using a very similar branding for both tobacco and non-tobacco products) to circumvent as well as violate the prohibition of 'indirect advertisements' under Section 5 of COTPA, much to their advantage. For the tobacco control community, the question remains as to what would be considered "genuine" brand extensions and "surrogate" advertisements. In this regard, on 16th July 2014, the MoIB issued the following statement in the Parliament of India: "The issue of defining genuine brand extensions of tobacco and alcohol products, as distinct from the products launched to promote the sale of tobacco, has been under consideration in the Ministry for some time (Ministry of Information and Broadcasting, 2014)." In light of the above statement, we can construe and draw a limited inference that surrogate advertising would be "products launched to promote the sale of tobacco".

On the basis of such inference, our attention is drawn to the many newly added non-tobacco products by the tobacco industry, specially smokeless tobacco companies, post the 2009 amendment of CTVN by MoIB. First example is of "chaini khaini". Please refer to Figures 1(a) and 1(b) for details. Both the brands are owned by Mahak group of companies and use the same punch line "Chen se Maza lo" ("enjoy with comfort") for marketing. The Mahak group has claimed protection by way of registration of trademark for the words "Chaini" and "Chaini Chaini" for various classes of products under the Trademarks Act in India. This is a common strategy followed by various smokeless tobacco industry players to promote/advertise their tobacco products in India.

Second example is of Vimal Panmasala (a betel nut product) and Vimal Elaichi (cardamom-based mouth freshener), manufactured by the company Vishnu Aromatics Limited. Originally, the company filed for Vimal Gutkha trademark registration in 1996. Please refer to Figure 2(a) for details. After the ban on Gutkha (a smokeless tobacco product having betel nut) vide Food Safety and Standards (Prohibition and Restrictions on Sales) Regulations 2011, the company came out with Elaichi (i.e., cardamom used commonly as mouth freshener in India) variant. Please refer to Figure 2(b) for details. As is clear from these figures, the colour scheme, the brand logo as well as the print and the calligraphy of the brand remains similar to its earlier Gutkha pouch. This is again a harsh example of the tobacco brand image being hammered into the minds of the people. Such title and colour scheme sharing between the tobacco and the non-tobacco product serves each and every purpose of direct advertisement. Notably, the brand was one of the six co-presenters of the Sony Pictures Sports Network (SPSN) channel's broadcast of the Indian Cricket Team's first international cricket series after a gap of almost nine months, tour to Australia, in the year 2020-21 (Insidesport, 2020). Also, the brand co-sponsored a major Bollywood event - the FILMFARE Awards 2019 - with the visuals just using the brand Vimal, without referring to any specific product. Please refer to Figures 2(c) and 2(d) for details.

The fact remains that it is difficult to ascertain the parameters on which an advertisement could be considered indirect or a genuine brand extension of tobacco products. These parameters of genuine brand extension as to the basis of granting the CBFC certificate to tobacco product brands (applied to non-tobacco products) such as Chaini Chai and Vimal Elaichi have never been reasoned by MoIB. The CBFC certification was issued to these brands but a certificate from a registered chartered accountant, as per Rule $7(\mathrm{~A})(\mathrm{v})(\mathrm{i})$ of CTVN, certifying that the product carrying the same name as cigarettes or tobacco products "is distributed in reasonable quantity" and "is available in substantial number of outlets" and that "the proposed expenditure on such advertising thereon shall not be disproportionate to the actual sales turnover of the product", was not available with CBFC. In fact, the biggest loophole is that it is almost impossible to put a mechanism in place to objectively determine the intangible assets such as "reasonable quantity", "substantial number of outlets", "proposed expenditure on advertising", and most importantly "whether such expenditure on advertising is disproportionate to the

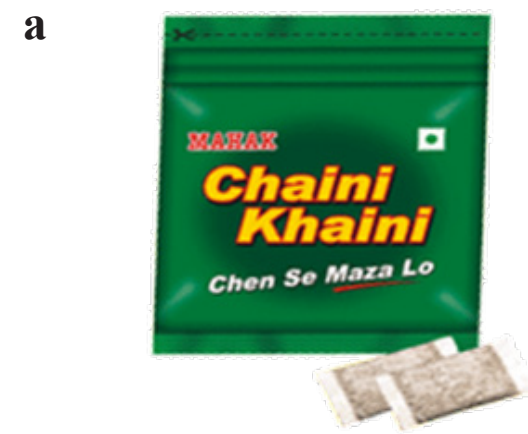

b

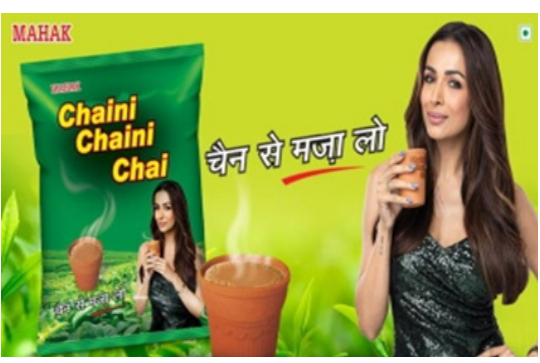

Figure 1. a, Chaini khaini, a smokeless tobacco product often advertised as a close variant of the "Swiss Snus" and registered under the Trademarks Act in 2006; b, Chaini Chaini Chai, a tea brand registered under the Trademarks Act in 2009, soon after the 2009 amendment of CTVN Rules

Asian Pacific Journal of Cancer Prevention, Vol 22 
Table 1. Showing Two Examples of Violation of TAPS Ban in Indonesia

\begin{tabular}{|c|c|c|c|}
\hline Image & Tobacco Brand & Name of Event & Violations \\
\hline$+2 k$ & (2) & $\begin{array}{l}\text { Badminton } \\
\text { Audition for Youth } \\
\text { sponsored by Djarum }\end{array}$ & $\begin{array}{l}\text { Article } 47 \text { (1) of Government } \\
\text { Regulation No. } 109 / 2012 \text { on the } \\
\text { prohibition to engage children under } 18 \\
\text { years old in tobacco sponsored event }\end{array}$ \\
\hline $\begin{array}{l}\text { Credit: Lentera Anak } \\
\text { Foundation }\end{array}$ & $\sin x$ 回 & & \\
\hline $\operatorname{lin}^{2}$ & persanks: & $\begin{array}{l}\text { Skateboard and BMX } \\
\text { competition sponsored by } \\
\text { Pro Mild }\end{array}$ & $\begin{array}{l}\text { Article } 36(1) \text { of Government Regulation } \\
\text { No.109/2012 on the prohibition to use } \\
\text { brand name and logo of a tobacco } \\
\text { product including brand image in a } \\
\text { tobacco sponsored event. }\end{array}$ \\
\hline $\begin{array}{l}\text { Credit: Lentera Anak } \\
\text { Foundation }\end{array}$ & 16 mans. & & \\
\hline
\end{tabular}

actual sales turnover of the product", all these being very subjective provisions. Unfortunately, the draft Central Consumer Protection Authority Guidelines 2020 uses similar phraseology and may practically prove to be non-effective in implementing robust TAPS ban in India. Thus, these Rules and related amendments have caused more confusion and have loopholes that are being fully exploited by the tobacco industry. The tobacco Industry is well aware of the absence of any mechanism in place to assess the market worth/income/turnover of a product qua its advertisement expenditure. This leaves a grey area for the tobacco industry to take advantage of and continue to practice surrogate, brand sharing, and brand extension advertisements in India.

The Advertising Standards Council of India (ASCI) is a voluntary self-regulation council, registered as a non-profit company under the Companies Act. It is formed to safeguard against the indiscriminate use of advertising for promoting products regarded as hazardous to society at large. Section 6 of the ASCI code specifically prohibits indirect advertising and lays down specific criteria to decide whether an advertisement is an indirect advertisement or not. However, ASCI, being a voluntary association, has only an advisory role and cannot have a deterrent effect at par with implementation of a legislation.

Over-the-top (OTT) is a means of providing television and film content over the internet at the request and to suit the requirements of the individual consumer. Recently, there has been a trend to increasingly display tobacco use scenes (including tobacco brand placements) on the OTT

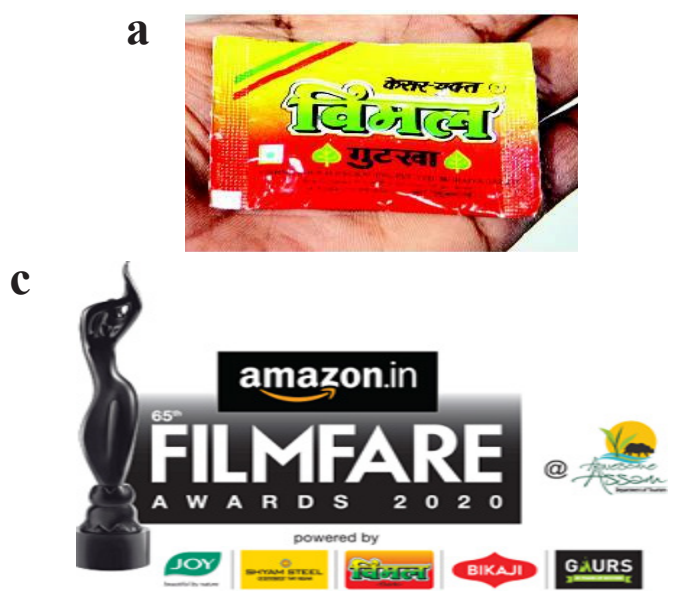

b

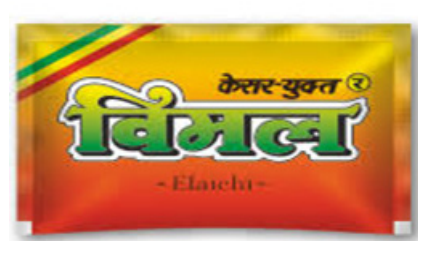

d

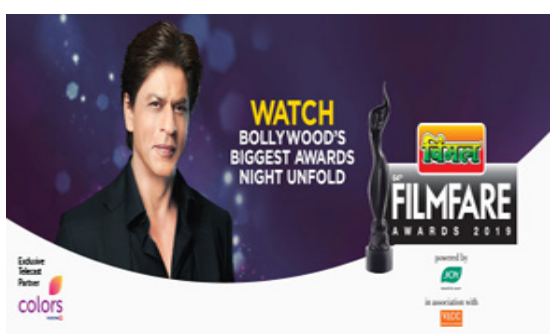

Figures 2. (a), Vimal Gutkha, a smokeless tobacco product registered under the Trademarks Act in 1996; (b), Vimal Elaichi (cardamom-based mouth freshener) with colour scheme, brand logo, print, and calligraphy similar to gutkha (smokeless tobacco) pouch; (c) and (d), Bollywood FILMFARE Awards 2020 co-sponsored by Vimal Brand, without referring to any specific product 
platforms. The Cabinet Secretariat, Government of India, vide notification dated 9th November, 2020 allocated the "Digital and Online media" to MoIB. Though the OTT platform is increasingly being used for advertising tobacco products, in the absence of any form of rules/ guidelines issued by the MoIB, it is difficult to regulate the content and recurring TAPS violations on such platforms. This platform was particularly exploited by the tobacco industry during the COVID-19-related lockdown periods when people were home-bound and accessed OTT content on a frequent basis.

\section{Indonesia}

While there is evidence of substantial tobacco industry interference in almost all the SEA countries, the level of interference in tobacco control policy in Indonesia is one of the highest (WHO, 2020). Indonesia is the only country in the Region which is not a Party to the WHO FCTC despite having one of the highest tobacco burden in the world. Tobacco companies in Indonesia showcase themselves as ethical corporations contributing to government revenue, enacting so-called corporate social responsibility programs, and awarding sponsorships. One of the arguments raised by the tobacco industry to discourage local governments in the country from banning TAPS is that it would eventually lead to decrease in government's overall revenue. Indonesia remains one of the few countries in the world that broadcast cigarette advertisements on television. The magnitude of cigarette business in Indonesia seems to be an important factor contributing to weak implementation of tobacco control laws. To give a perspective, Indonesia is the second largest cigarette market in the world, with an overall retail volume of 316.1 billion sticks per year in 2016 (Astuti et al., 2020). Barring outdoor tobacco advertising, Indonesia has not adopted a comprehensive ban on TAPS.

Government Regulation of the Republic of Indonesia No. 109 of 2012 concerns with addictive substances in tobacco products in the interests of health. It was issued under Law No. 36 of 2009 concerning health. Some provisions entered into force immediately, including a ban on single stick sales of machine-manufactured white cigarettes. Provisions placing further restrictions on TAPS entered into force on December 24, 2013. Provisions requiring pictorial health warnings entered into force in June 2014 (via Ministry of Health Decree No. 28 of 2013). Regulation of the Minister of Health No. 28 of 2013 concerns health warnings and health information on tobacco product packaging and contains implementing details for pictorial health warnings. Regulation No. 28 of 2013 was subsequently amended by Regulation of the Minister of Health No. 56 of 2017. Also, Food and Drugs Supervisory Agency Regulation No. 41 of 2013 concerns supervision of tobacco products in distribution, the inclusion of health warnings in advertisements and tobacco product packaging, and promotions and contains details on monitoring and enforcement authority of the Food and Drugs Supervisory Agency under Government Regulation (PP) No. 109 of 2012.

Thus, Government Regulation (PP) No. 109 of 2012 issued under the 2009 Health Law is the primary governing regulation on TAPS ban in Indonesia. In addition, TAPS are regulated by three more laws: Law No. 40 of 1999 concerning Press, Law No. 32 of 2002 concerning Broadcasting, and Law No. 33 of 2009 concerning Films. Article 36 of the Government Regulation (PP) No. 109 of 2012 reads that "Any person who produces and/or imports tobacco products and/or who sponsors an institutional and/ or individual activity may do so only under the following conditions: a. not use the trademarked names and logos of tobacco products including tobacco product brand images; and b. not have the intent to promote tobacco products. Additionally, sponsorship is prohibited for institutional and/or individual activities that are covered by the media. However, progress on TAPS ban has been slow in Indonesia as it is influenced by players such as media and advertising companies and sponsorship recipients who benefit from tobacco advertising and marketing (WHO, 2018).

The current national-level tobacco control regulation, PP 109/2019, is a joint regulation concerning three ministries and is more of a compromised outcome. Besides being weak on several tobacco control aspects, the regulation is vague and provides significant loopholes to the tobacco industry during various stages of implementation. Moreover, most elements of PP 109/2019 require further regulatory action at either the national or sub-national level in order to be implemented. Some aspects of the mandate under PP have been extended to the sub-national level, which makes sense given the decentralized structure of the government in Indonesia. However, this leads to delays in policy formulation and policy implementation owing to large number of cities/districts in the country, lack of political will at different levels, and potency of tobacco industry interference (political lobbying) at sub-national levels. Additionally, the current regulation mandates that different government agencies handle different aspects of implementation. This is further confounded by unclear descriptions within the regulation allowing agencies to forego their responsibilities. In fact, the PP legislation has crippled the role of Indonesian Food and Drug Monitoring Agency (BPOM). BPOM can issue a warning letter but cannot impose any further sanctions, as other agencies have the mandate for enforcement oversight. For example, the Indonesian Broadcasting Commission (KPI) would monitor violations of broadcast media advertisements and sub-national governments are responsible for any outdoor advertisements. This diversification of power among different monitoring agencies preclude a single effective focal agency to pursue and oversee the implementation of laws and bye-laws laid down to address TAPS in Indonesia (Astuti et al., 2020).

However, some cities in Indonesia have taken initiatives to address TAPS in their respective jurisdictions. Bogor city has effectively banned tobacco advertisements in its jurisdiction. Also, the trend consistently shows an increase in tobacco tax revenues even when tobacco advertisements were completely banned in Bogor, contrary to what tobacco industry claims in Indonesia. In 2013, the tobacco tax revenue was IDR 464 billion. Despite an effective ban on tobacco advertisements, the revenue reached IDR 784 billion in 2016. Also, in 2015 in 
Jakarta, as a result of intensive advocacy by civil society, Governor issued Governor Regulation No. 1 Year 2015 banning outdoor tobacco advertising and shortly after, issued Governor Regulation No. 244 Year 2015 sharing the implementation guidelines for the ban. As Jakarta is home to 12 million people, the ban is a significant public health milestone. The tax office and civil police were engaged in the enforcement of this regulation. The locations of billboards depicting tobacco advertisements were identified and the contract end date was monitored for each of the advertisements. When the contract ended, the civil police removed that specific advertisement. The civil society regularly collaborated with tax office and civil police to monitor the status of these removals. After an year of intensive enforcement, as many as 4,861 tobacco billboards were removed and Jakarta became free from tobacco advertising. Recently, local authorities in Jakarta further strengthened the enforcement of banning outdoor advertisements by building capacity among local government officials and conducting regular enforcement drives. They also developed a simple, phone-based application to support enforcement of the outdoor ban. The city aims to achieve $90 \%$ compliance with both indoor and existing outdoor bans on tobacco advertising (WHO, 2021). Elsewhere, in Kulonprogo, the prevailing smoke-free law includes provisions of ban on outdoor tobacco advertising. Under this law, outdoor tobacco advertisements within smokefree areas are banned. Mayor of Kulonprogo proactively issued series of Mayor's decrees, which in part instructed removal of all outdoor tobacco advertisements. The Mayor established a team to monitor implementation of the law, and one of team's responsibilities was to identify and remove all outdoor tobacco advertisements. To socialize this new policy, Mayor himself went in the field to remove a giant tobacco billboard and replace it with anti-smoking advertisement. Tobacco banners and stickers placed in kiosks were removed and replaced with stop-smoking banners. In 2015, the local police in Kulonprogo removed as many as 1,977 tobacco advertisements: 1,964 banners, 9 billboards, and 4 signage boards. However, apart from these few examples, TAPS ban in general remains weak in Indonesia (WHO, 2018; WHO 2020). Table 1 shares two examples of violation of TAPS ban in Indonesia.

\section{Where we need to go}

Research corroborates that advertising bans work best when they are comprehensive (Stubbs, 2021). Thus, circumvention of Section 5 of COTPA by tobacco industry in India through surrogate, brand sharing, and brand extension advertisements needs to be immediately addressed. In judging whether or not any particular advertisement is an indirect advertisement for a tobacco product, due attention should be paid to: (a) any nontobacco product or service of any feature, its similarity or likelihood of being mistaken for, or connected with a tobacco product which is prohibited (b) whether the purpose or effect of that use is to promote a tobacco product or not. Thus, the only real and effective way to counter the existing loopholes is an improved legislation that bans advertising of product, service, or event which has or shares a name or a trademark that has been registered and approved for a tobacco product anywhere in India. This would leave no loopholes for exploitation and will effectively regulate two powerful sectors: tobacco industry and the media - one rich and the other influential. The United Kingdom has a brand sharing legislation in place called The Tobacco Advertising and Promotion (Brandsharing) Regulations 2004, which has been into effect since July 2005. The same can be used as a reference. Notably, the Regulation 3 of this legislation describes Brandsharing as "the use by a person in connection with any non-tobacco product or service of any feature which is the same as, or is so similar as to be likely to be mistaken for, any feature which is connected with a tobacco product is prohibited if the purpose or effect of that use is to promote a tobacco product in the United Kingdom through the association which it has with any non-tobacco product or service (The National Archives of Government of United Kingdom, 2004)." Also, the proposed improved legislation in India should completely prohibit "PoS advertising" of tobacco products and unabated display of tobacco use scenes and tobacco brand placements on the OTT platforms.

Legitimate business diversification and curtailment of the trademark rights are the two defenses which may come to the forefront while enacting concrete laws on brand sharing. We need to be clear here that by specifically legislating against brand sharing of tobacco products, we are not stopping legitimate business diversification. If a tobacco company wishes to diversify into other goods, that is perfectly legitimate as long as the tobacco brand is not used. Therefore, the policy makers need to understand that prohibition on brand sharing will not stop legitimate business diversification. An example could be of Godfrey Phillips India, which owns "Marlboro" as well as the retail outlets " 24 SEVEN". The latter is not brand sharing because "24 SEVEN" does not have the same branding as Godfrey Phillips' tobacco products. But "Raag Gold Panmasala" and "Ragaa Gold Zarda" is brand sharing in context of segment similarity as well as on grounds of prior marketing of the tobacco product.

The Trademarks Act, 1999 allows a single brand to be registered for more than one product, allowing the tobacco industry to register and advertise for non-tobacco products with the same brand name as the tobacco products. The primary function of a trademark is to act as an indicator of the source of origin of the goods. The secondary function of a trademark is to act as a "silent salesman", i.e., display of the logos and marks of a brand on packaging and colour scheme of branding, etc. act as an advertisement for a company. This secondary function is what tobacco companies exploit in brand extensions and brand sharing. By covertly displaying their trademarks, companies advertise products they would otherwise not be able to. It may be noted that trademark, in general, gives the holder the right to exclude any other person from using it, but does not bestow upon him/her the positive right to use his/her trademark wherever he/she so wishes. However, Section 2(zb) of India's Trademarks Act, 1999 provides a positive right too and bestows upon the proprietor to use the mark. Still, the right to use a trademark is not an 
absolute right; it cannot be treated at par with the citizens' right to life and right to health (Mitchell and MaidanaEletti, 2014). Thus, it can be restricted over concerns of public health and wellbeing. It may be underscored here that the Australian Trademarks Act like India's is also positively worded, even then Australia is the pioneer of plain packaging in the world (WTO, 2018). Thus, in spite of a partial contradiction in the law, as the Trademarks Act 1999 is positively worded whereas COTPA prohibits the use of certain trademarks for promoting tobacco products, these legislations can be harmoniously interpreted and the more specific legislation (COTPA) shall prevail. However, in order to discourage litigation and prevent conflict, the Legislature in India can consider amending the Trademarks Act as well.

At the very least, the rules regarding "brand extension" advertisements must be made stricter in India. As prescribed by the ASCI, a mechanism for carrying out cost benefit analyses of these advertisements need to be carried out. For example, the annual cost of advertising Pan Parag's Plain Panmasala (a non-tobacco product) on just two television channels was 3.8 times its annual sales (Sushma and Sharang, 2004). It thus becomes clear that such products are being used as surrogates to advertise the tobacco products sold with the same branding. Similarly, Chaini Chaini Tea is hardly available in the market, where as Chaini Khaini, a tobacco product, is available at almost all points of sales of tobacco products in India.

In Indonesia, over the years, tobacco companies have substantially influenced both policy decisions and public perceptions, signifying a power imbalance within the government system and broader networks. Acceding to and enforcing the WHO-FCTC would be the best way forward and would enable the government of Indonesia to shift the power imbalance towards public health stakeholders. Tobacco control advocates must enhance their network cohesion and embrace other community groups to improve engagement and communication with policymakers.

The government of Indonesia must increase its commitment to comprehensive TAPS ban if it hopes to stem the rising tobacco epidemic and to harness the benefits of the predicted demographic dividend - the working age group will reach $70 \%$ of the population by 2030 (Ginting et al., 2018). However, Indonesia has failed to significantly move the TAPS ban agenda under the current national laws as it requires amendment of the Broadcasting and the Press laws. However, a provision under the current PP mandates subnational governments to 'further' regulate TAPS within their jurisdiction. Thus, the subnational governments can impose effective TAPS bans on outdoor media and PoS. More and more cities/districts have started banning TAPS. However, more effective legislations, including amendments as needed, comprehensively banning all forms of TAPS and clearly demarcating roles and responsibilities of different government regulatory bodies need to be adopted at national and subnational levels to realistically take this agenda forward.

This should be followed by effective implementation of these legislations. To this end, as proposed by Hoe et al, the most effective approach would be the one that addresses all the factors influencing implementation fidelity: institutional capacity, operational effectiveness, social climate, tobacco industry interference, and political commitment (Hoe et al., 2019). Notably, all these factors are interrelated. Political commitment for effective implementation can influence the number of resources dedicated to TAPS ban in Indonesia, thereby enhancing institutional capacity and operational effectiveness. It can have a direct impact on the population's acceptance of the measures aimed at comprehensive TAPS ban. Committed leaders will in turn cultivate an environment that diminishes tobacco industry interference by strictly adhering to FCTC Article 5.3. Likewise, enhanced institutional capacity and operational effectiveness in respect of implementing comprehensive TAPS ban can help foster a receptive social climate and address industry interference through both effective enforcement and public education. It also has the potential to influence political commitment through the presence of an empowered network of stakeholders and political constituents.

\section{Disclaimer}

The opinions or views expressed in this article are solely those of the author(s) and do not express the views or opinions of the organization to which the authors are affiliated.

\section{Author Contribution Statement}

The authors confirm contribution to the paper as follows: Study was conceived by JK. First draft was prepared by SC and improved by AVR. Special inputs were added by JK and VP. All authors reviewed and approved the final version of the manuscript.

\section{Acknowledgements}

Authors would like to sincerely thank Mr Praveen Sinha from WHO Country Office India and Ms Dina Kania and Dr Farrukh Qureshi from WHO Country Office Indonesia for all their support.

The publishing cost was provided by WHO office in South-East Asia.

\section{References}

Astuti PAS, Freeman B (2018). Tobacco company in Indonesia skirts regulation, uses music concerts and social media for marketing. United Kingdom: The Conversation Trust, 2018.

Astuti PAS, Assunta M, Freeman B (2020). Why is tobacco control progress in Indonesia stalled? - a qualitative analysis of interviews with tobacco control experts. BMC Public Health, 20, 527.

Ginting E, Manning C, Taniguchi K (2018). Indonesia: Enhancing productivity through Quality Jobs. Asian Development Bank, Manila, Philippines. doi: 10.22617/ TCS189213-2.

Hoe C, Kennedy RD, Spires M, Tamplin S, Cohen JE (2019). Improving the implementation of tobacco control policies in low-and middle-income countries: A proposed framework. BMJ Glob Health, 4, e002078.

Asian Pacific Journal of Cancer Prevention, Vol 22 
Insidesport (2020). India vs Australia Series: Sony signs 15 sponsors, Ather Energy to advertise first time on cricket. Available from: https://www.insidesport.co/india-vsaustralia-series-sony-signs-15-sponsors-ather-energy-toadvertise-first-time-on-cricket/ (last accessed 18 August 2021).

Kaur J, Rinkoo AV (2017). Getting real with the upcoming challenge of electronic nicotine delivery systems: The way forward for the South-East Asia region. Indian J Public Health, 61, 7-11.

Kaur J, Thamarangsi T, Rinkoo AV (2017). Regulating smokeless tobacco and processed areca nut in South-East Asia region: The journey so far and the road ahead. Indian J Public Health, 61, 3-6.

Khariwala SS, Garg A, Stepanov I, et al (2016). Point-of-sale tobacco advertising remains prominent in Mumbai, India. Tob Regul Sci, 2, 230-8.

Kickbusch I, Allen L, Franz C (2016). The commercial determinants of health. Lancet Glob Health, 4, 895-6.

Ministry of Information and Broadcasting, Government of India (2014). Response to parliament question on surrogate advertising. Available from: http://loksabhaph. nic.in/Questions/QResult15.aspx?qref=1109\&1sno=16 (last accessed 16 August 2021).

Ministry of Information and Broadcasting, Government of India (2020). Advisory on surrogate advertisements of prohibited products on private satellite TV channels. Available from: https://mib.gov.in/sites/default/files/ADVISORY\%20 ON\%20SURROGATE\%20ADVERTISEMENTS.pdf (last accessed 17 August 2021).

Mitchell A and Maidana-Eletti M (2014). Plain Packaging in Australia: Implications for Polanska K and Kaleta D (2021). Tobacco and E-Cigarettes Point of Sale AdvertisingAssessing Compliance with Tobacco Advertising, Promotion and Sponsorship Bans in Poland. Int J Environ Res Public Health, 18, 1976.

Septiono W, Kuipers MAG, Ng N, Kunst AE (2021). Self-reported exposure of Indonesian adolescents to online and offline tobacco advertising, promotion and sponsorship (TAPS). Tobacco Control Published Online First: 19 February 2021. doi: 10.1136/tobaccocontrol-2020-056080

Stubbs T (2021). Commercial determinants of youth smoking in ASEAN countries: A narrative review of research investigating the influence of tobacco advertising, promotion, and sponsorship. Tob Induc Dis, 61. doi: $10.18332 / \mathrm{tid} / 139124$.

Sushma C, Sharang C (2004). Pan masala advertisements are surrogate for tobacco products. Indian J Cancer, 42, 94-8.

The National Archives of Government of United Kingdom (2004). The Tobacco Advertising and Promotion (Brandsharing) Regulations 2004. Available from: https://www.legislation. gov.uk/uksi/2004/1824/made (last accessed 17 August 2021)

Trademark Rights under the TRIPS Agreement and the Paris Convention. Anuario Andino de Derechos Intelectuales. Año X - N. ${ }^{\circ}$ 10. Lima, 2014, 295-303. Available from: http://www.anuarioandino.com/Anuarios/Anuario10/Art10/ ANUARIO\%20ANDINO\%20ART10.pdf(last accessed 17 August 2021).

World Health Organization (2013a). Banning tobacco advertising, promotion and sponsorship: what you need to know. Geneva: World Health Organization. Available from: https://apps.who.int/iris/bitstream/handle/10665/83779/ WHO_NMH_PND_13.1_eng.pdf (last accessed 13 August 2021).

World Health Organization (2013b). Global action plan for the prevention and control of noncommunicable diseases 20132020. Geneva: World Health Organization. Available from: https://www.who.int/publica tions/i/item/9789241506236 (last accessed 14 August 2021).

World Health Organization (2013c). WHO report on the global tobacco epidemic 2013: enforcing bans on tobacco advertising, promotion and sponsorship. Geneva: World Health Organization. Available from: https://apps.who.int/ tobacco/global_report/2013/en/index.html (last accessed 8 July 2021).

World Health Organization (2018). Implementation of WHO MPOWER package in the South-East Asia Region: a progress report. World Health Organization. Regional Office for South-East Asia. Available from: https://apps.who.int/ iris/handle/10665/274278 (last accessed 6 August 2021).

World Health Organization (2019). WHO global report on trends in prevalence of tobacco use 2000-2025, third edition. Geneva: World Health Organization. Available from: https:// www.who.int/publications/i/item/who-global-report-ontrends-in-prevalence-of-tobacco-use-2000-2025-thirdedition (last accessed 7 July 2021).

World Health Organization (2020). The Tobacco AtlasPerspectives from the South-East Asia Region. World Health Organization, Regional office for South-East Asia. Available from: https://www.who.int/southeastasia/publications-detail/ sear-tobacco-atlas (last accessed 21 July 2021).

World Health Organization (2021). WHO report on the global tobacco epidemic 2021: addressing new and emerging products. Geneva: World Health Organization. Available from: https://www.who.int/publications/i/ item/9789240032095 (last accessed 15 July 2021).

World Trade Organization (2018). Australia - certain measures concerning trademarks, geographical indications and other plain packaging requirements applicable to tobacco products and packaging. Available from: https://www. tobaccocontrollaws.org/litigation/decisions/au-20180628australia---tobacco-plain-pack (last accessed 19 August 2021).

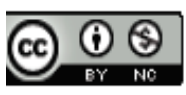

This work is licensed under a Creative Commons AttributionNon Commercial 4.0 International License. 